\title{
A Design and Simulation Tool for Ground Source Heat Pump Systems Considering Groundwater Advection
}

\author{
Yutaka SHOJ I \\ Katsunori NAGANO, PhD
}

\author{
Takao KATSURA, PhD \\ Yoshitaka SAKATA, PhD
}

Takashi HI GASHI TANI

\begin{abstract}
Calculation of the underground temperature resulting from heat injection/ extraction into/from ground heat exchangers (GHEXs) with hourly variation is one of the most noteworthy challenges to address when simulating and designing a ground source heat pump (GSHP) system. Especially in Japan, considering the groundwater flow is desirable because there is the possibility to reduce the installation cost for GSHP system. In order to overcome this challenge, the authors introduce a method to calculate the underground temperature, by considering heat injection/extraction into/from GHEXs with hourly variation. The method applies the superposition of the Moving Infinite Cylindrical Source (MICS) solution and the Moving Infinite Line Source (MILS) solution to calculate the temperature change due to heat injection/extraction into/from the certain GHEX and other neighboring GHEXs, respectively. In this paper, the outlines of the MICS and the method that calculate the MICS solution were firstly introduced. Next, the calculation method of underground temperature and the simulation model for the GSHP system were explained. Finally, the temperature variations of the heat carrier fluid were calculated by changing the conditions the geological layer and groundwater velocity.
\end{abstract}

\section{NTRODUCTI ON}

GSHP systems have gained attention in Japan since ground thermal energy was defined as one of the renewable energies in 2009. However, the number of GSHPs installed in Japan is much smaller than the number in other countries such as the USA, China, and Sweden due to the expensive installation cost of GHEXs. In order to reduce the installation cost, considering the groundwater flow in the design process is the one of effective methods. There are several research works related to the effect of ground water flow to the GHEXs (Gehlin and Hellström, 2003), (Diao et.al, 2004), (Molina-Giraldo et.al, 2011). However, the research works related to the simulation tool for the GSHP system considering groundwater flow are hardly observed. The authors developed the simulation tool for the GSHP system considering groundwater flow. In this paper, the outlines of calculation method and example of simulation for the GSHP system are explained.

\section{CALCULATI ON OF UNDERGROUND TEMPERATURE CONSI DERI NG SI NGLE GEOLOGI CAL LAYER WITH GROUNDWATER FLOW}

\section{Types of groundwater flow}

There are several types of groundwater flow (Gehlin and Hellström, 2003). In Japan, Darcy flow through the porous media is majority and there is quite a lot of case where the the groundwater flow with the Darcy velocity of more than 100 $\mathrm{m} /$ year is observed. Therefore, in this paper, the calculation of underground temperature considering groundwater flow of 
Darcy flow through the porous media is treated.

\section{Calculation of underground temperature considering heat injection into GHEX with constant heat flux and groundwater advection}

The groundwater flow is regarded as Darcy flow through the porous media. In this case, an incompressible, constantproperty fluid flow passes through a saturated, homogeneous, and infinite porous medium. The incoming free velocity of the fluid $u_{\infty}$ is parallel to the $x$ axis and the following equation is obtained.

$u=-k \frac{d h}{d x}$

On the other hand, the GHEX is regarded as a hollow cylinder in the porous media. In this case, the fluid dynamics is analogous to the one referring to the traditional problem of the two-dimensional, incompressible, irrotational flow past a circular cylinder. The analytical expression of the velocity potential is (Bruce et.al, 2009);

$\emptyset=u_{\infty}\left\{1+r_{p-\text { out }} /\left(x^{2}+y^{2}\right)\right\} x$

With regard to the heat transfer in the ground surrounding GHEX, we firstly consider a constant heat flux $q$ at the cylinder surface. The energy equation can be formulated according to the local thermal equilibrium, in which both solid and fluid phases have the same local temperature. Under the assumption, the following equations can be obtained.

$c_{s} \rho_{s} \frac{\partial T_{s}}{\partial t}+c_{w} \rho_{w}\left(\nabla T_{s}\right)(\nabla \varnothing)=\nabla\left(\lambda_{s} \nabla T_{s}\right)$

And in the case of $r=0$, this problem becomes the moving infinite line source (MILS). Carslaw and Jeager introduce the analytical solution of this problem (Carslaw and Jaeger, 1959). Diao et.al., apply the MILS to the calculation of underground temperature surrounding the GHEX, which is affected by the groundwater advection (Diao et.al, 2004). The energy equation can be translated as Equation (4).

$c_{s} \rho_{s} \frac{\partial T_{s}}{\partial t}+c_{w} \rho_{w}\left(\frac{\partial T_{s}}{\partial x}\right)\left(k \frac{\partial h}{\partial x}\right)=\nabla\left(\lambda_{s} \nabla T_{s}\right)$

Then, the analytical solution of MILS $\Delta T_{S-M I L S}(x, y, t)$ can be expressed by the following equation if the constant heat $\mathrm{q}$ is generated at $r=0$ (Diao et.al, 2004).

$\Delta T_{S-M I L S}(x, y, t)=$

$\frac{q}{4 \pi \lambda_{s}} \int_{0}^{\frac{4 a_{S} t}{r^{2}}} \frac{1}{\left(t-t^{\prime}\right)} \exp \left[-\frac{\left\{x-U\left(t-t^{\prime}\right)\right\}^{2}+y^{2}}{4 a_{S}\left(t-t^{\prime}\right)}\right] d t^{\prime}$

Here, $U=u_{\infty} c_{w} \rho_{w} /\left(c_{s} \rho_{s}\right)$.

Meanwhile, in the case of $r \neq 0$, this problem is called as the moving infinite cylindrical source (MICS) and the analytical solution of this problem has not been obtained (Conti et.al, 2018). However, the authors assumed that the superposition of the MICS is possible as well the superposition of the infinite line source (ILS), the infinite cylindrical source (ICS), and the MILS (Katsura et.al, 2006). Then, the temperature field of MICS was calculated by the numerical model shown in

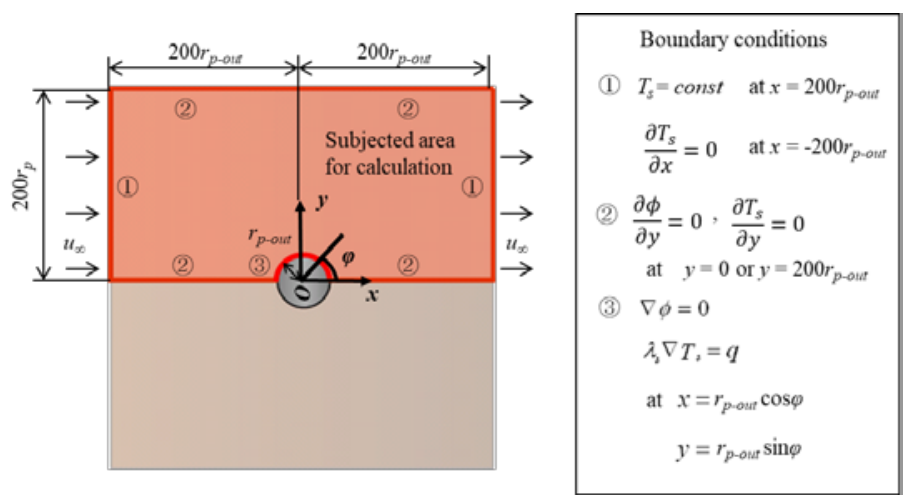

Figure 1 Subjected area for numerical calculation and boundary conditions 
Figure 1 (Katsura et.al, 2006) and the result was compared to the temperature filed obtained by experiment with a thermal probe (Katsura et.al, 2006) and the analytical MILS model. The temperature fields indicated good agreement to each other.

However, the difference of temperature fields between MICS and MILS increases when the radius of cylindrical source becomes larger. On the other hand, it is difficult to apply the MILS for the calculation of underground temperature considering heat injection/extraction into/from GHEX with hourly variation as well the ILS. Therefore, in order to calculate the underground temperature considering heat injection/extraction into/from GHEX with hourly variation, the temperature at $r=r_{p \text {-out }}$ in the MICS is approximated by modifying the temperature at $r=r_{p \text {-out }}$ in the ICS, which is obtained by the analytical solution (Carslaw and Jaeger, 1959). If the modification coefficient $C_{c}$ that can modify from the temperature at $r=r_{p-o u t}$ in the ICS to the temperature at $r=r_{p \text {-out }}$ in the MICS is assumed, the average temperature at $r=r_{p-o u t}$ with constant heat flux $q$ in the MICS can expressed by the following equation.

$\Delta T_{s-M I C S}\left(r_{p-o u t}, t\right)=\Delta T_{s-I C S}\left(r_{p-o u t}, t\right) C_{c}=\frac{1}{\pi^{2} r_{p-o u t} \lambda_{s}} q I\left(r_{p-o u t}, t\right) C_{C}$

Now,

$I(r, t)=\int_{0}^{\infty}\left(1-e^{-a_{s} \beta^{2} t}\right) \frac{J_{0}(\beta r) Y_{1}\left(\beta r_{p-o u t}\right)-Y_{0}(\beta r) J_{1}\left(\beta r_{p-o u t}\right)}{u^{2}\left[J_{1}^{2}\left(\beta r_{p-o u t}\right)+Y_{1}^{2}\left(\beta r_{p-o u t}\right)\right]} d \beta$

If $u_{\infty}=0, C_{c}=1$ and Equation (6) is the same as the analytical solution of the ICS. In addition, if we introduce the dimensionless quantities $t_{p-o u t}^{*}=a t / r_{p-o u t}{ }^{2}, r_{p-o u t}^{*}=r_{p-o u t} / r_{p-o u t}=1$, and $T_{s-I C S}^{*}\left(1, t_{p-o u t}^{*}\right)=$ $2 \pi \lambda_{s} \Delta T_{s-I C S}\left(r_{p-o u t}, t\right) / q\left(\Delta T_{s-I C S}\left(r_{p-o u t}, t\right)=\frac{q}{\pi^{2} r_{p-o u t, i} \lambda_{s}} I\left(r_{p-o u t, i}, t\right)\right)$, Equation (6) is translated as the following equation. Then, the modification coefficient can be organized by using the dimensionless parameters $r_{p-o u t}^{*}=1$,

$R_{p-o u t}^{*}=U r_{p-o u t}^{*} / a_{s}$, and $F_{O}=U^{2} t / a_{s}$ as shown in Equation (7).

$T_{s-M I C S}^{*}\left(1, t_{p-\text { out }}^{*}\right)=T_{s-I C S}^{*}\left(1, t_{p-\text { out }}^{*}\right) C_{C}^{*}\left(1, R_{p-\text { out }}^{*}, F_{O}\right)$

The modification coefficient $C_{C}^{*}\left(1, R_{p-o u t}^{*}, F_{O}\right)$ is obtained by comparing $T_{s-I C S}^{*}\left(1, t_{p-\text { out }}^{*}\right)$ and $T_{s-M I C S}^{*}\left(1, t_{p-\text { out }}^{*}\right)$. Here, $T_{S-M I C S}^{*}\left(1, t_{p-\text { out }}^{*}\right)$ is calculated by the numerical model introduced above. After the comparison, $C_{C}^{*}\left(1, R_{p-o u t}^{*}, F_{O}\right)$ is approximated as the function of $1, R_{p-o u t}^{*}$, and $F_{O}$.

$C_{C}^{*}\left(1, R_{p-\text { out }}^{*}, F_{O}\right) \cong f\left(1, R_{p-\text { out }}^{*}, F_{O}\right)$

\section{Calculation of underground temperature considering heat injection/ extraction into/ from multiple GHEXs with hourly variation and groundwater advection}

Figure 2 shows the multiple GHEXs buried in a random layout. The ground is regarded as an infinite medium and superposition of the temperature field in space is applied. Thus, in the case where $m$ GHEXs are placed underground as shown in Figure 2, the soil temperature change on the surface of the certain GHEX can be calculated using the following equation.

$\Delta T_{s, i}\left(r_{p-o u t, i}, t\right)=\Delta T_{s, i, i}\left(r_{p-o u t, i}, t\right)+$ $\sum_{j=1}^{m} \Delta T_{s, i, j}\left(r_{d, i, j}, t\right)$

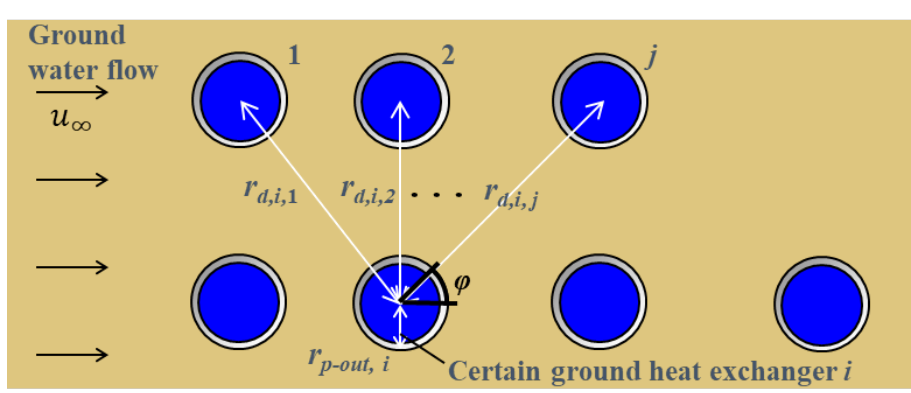

Figure 2 Multiple GHEXs buried in a random layout 
Where the subscript $i$ indicates the GHEX under consideration, $j$ indicates a neighboring GHEX, and $j \neq i$. The first term on the right side shows the change in temperature due to the heat injection/extraction of the GHEX under consideration and the second term is the temperature change due to the heat injection/extraction of the neighboring GHEXs. When the free velocity $u_{\infty}$ is zero, the temperature change in the first term on the right side of can be calculated from the following equation, applying the principle of superposition based on the solution of MICS and Duhamel's theorem.

$\Delta T_{s, i, i}\left(r_{p-o u t, i}, t\right)=\frac{1}{\pi^{2} r_{p-o u t, i} \lambda_{s}} \int_{0}^{t} q_{i}(\tau) \frac{\partial I\left(r_{p-o u t, i}, t-\tau\right) C_{c}}{\partial t} d \tau$

$q_{i}(\tau)$ is the heat injection/extraction into/from the certain GHEX $i$ at time $t=\tau$, and $\frac{1}{\pi^{2} r_{p-o u t, i} \lambda_{s}} q_{i}(\tau) \frac{\partial I\left(r_{p-o u t, i}, t-\tau\right)}{\partial t}$ indicates the amount of temperature change at the surface of the certain GHEXi caused by the heat injection/extraction at time $t=\tau$. Here, if the heat injection/extraction from the surface of the underground heat exchanger is considered to occur in a step-wise manner, as shown in Figure 10, Equation (10) can be simplified as in Equation (11) (Li et.al, 2015).

$\Delta T_{s, i, i}\left(r_{p-o u t, i}, t\right) \cong \frac{1}{\pi^{2} r_{p-o u t, i} \lambda_{s}} \sum_{l=1}^{n} q_{l, i} I\left(r_{p-o u t, i}, t-t_{l-1}\right)-I\left(r_{p-o u t, i}, t-t_{l}\right)$

Here, $q_{l, i}$ is the average quantity of heat injection/extraction from the considered GHEX $i$ in the interval $\Delta t_{l}$. By introducing the dimensionless quantities $t_{p-\text { out }}^{*}=a t / r_{p \text {-out }}{ }^{2}, r_{p-\text { out }}^{*}=r_{p-\text { out }} / r_{p-\text { out }}=1$, and $T_{s-I C S}^{*}\left(1, t_{p-\text { out }}^{*}\right)=$ $2 \pi \lambda_{s} \Delta T_{s-I C S}\left(r_{p-\text { out }}, t\right) / q_{l}\left(\Delta T_{s-I C S}\left(r_{p-o u t}, t\right)=\frac{q_{l}}{\pi^{2} r_{p-o u t, i} \lambda_{s}} I\left(r_{p-o u t, i}, t\right)\right)$, Equation (11) can be translated to the following equation (Katsura et. al, 2018).

$\Delta T_{s, i, i}\left(r_{p-o u t, i}, t\right) \cong \frac{1}{2 \pi \lambda_{s}} \sum_{l=1}^{n} q_{l, i}\left\{T_{s-I C S}^{*}\left(1, t_{p-o u t}^{*}-t_{p-o u t, l-1}^{*}\right)-T_{s-I C S}^{*}\left(1, t_{p-\text { out }}^{*}-t_{p-o u t, l}^{*}\right)\right\}$

If the free velocity $u_{\infty}$ is not zero, the temperature change $\Delta T_{s, i, i}\left(r_{p-o u t, i}, t\right)$ can be calculated by changing from $T_{s-I C S}^{*}\left(1, t_{p-o u t}^{*}-t_{p-o u t, l}^{*}\right)$ to $T_{s-M I C S}^{*}\left(1, t_{p-o u t}^{*}-t_{p-o u t, l}^{*}\right)$ in Equation (13) and substituting Equation (8). The equation is,

$\Delta T_{s, i, i}\left(r_{p-o u t, i}, t\right) \cong \frac{1}{2 \pi \lambda_{s}} \sum_{l=1}^{n} q_{l, i}\left\{T_{s-M I C S}^{*}\left(1, t_{p-o u t}^{*}-t_{p-o u t, l-1}^{*}\right)-T_{s-M I C S}^{*}\left(1, t_{p-\text { out }}^{*}-t_{p-\text { out }, l}^{*}\right)\right\}$

$\cong \frac{1}{2 \pi \lambda_{s}} \sum_{l=1}^{n} q_{l, i}\left\{T_{S-I C S}^{*}\left(1, t_{p-\text { out }}^{*}-t_{p-\text { out }, l-1}^{*}\right) C_{C}^{*}\left(1, R_{p-\text { out }}^{*}, F_{O, l-1}\right)-T_{s-I C S}^{*}\left(1, t_{p-\text { out }}^{*}-t_{p-\text { out }, l}^{*}\right) C_{C}^{*}\left(1, R_{p-o u t}^{*}, F_{O, l}\right)\right\}$

Here, $F_{O, l}=U^{2} t_{l} / a_{s}$ and $F_{O, l-1}=U^{2} t_{l-1} / a_{s}$.

Next, the second term on the right side of Equation (9) which denotes the temperature change due to the extraction and injection of heat of the neighboring GHEX $j$ is calculated from the following equation, applying the MILS analysis solution and the principle of superposition.

$\Delta T_{s, i, j}\left(r_{d, i, j}, t\right)=\int_{0}^{t} q_{i}(\tau) \frac{\partial \Delta T_{s-M I L S}\left(r_{d, i, j}, t-\tau\right)}{\partial \tau} d \tau$

Here, $\Delta T_{s-M I L S}\left(r_{d, i, j}, t\right)$ can be obtained as the following equation if $r_{d, i, j}^{2}=\sqrt{x^{2}+y^{2}}$ and $\beta=4 a_{s}\left(t-t^{\prime}\right) / r_{d, i, j}^{2}$ are substituted in Equation (5).

$\Delta T_{S-M I L S}\left(r_{d, i, j}, t\right)=\frac{1}{4 \pi \lambda_{s}} \exp \left(\frac{U r_{d, i, j}}{2 a_{s}} \cos \varphi\right) \int_{0}^{\frac{4 a_{s} t}{r_{d, i, j}^{2}}} \frac{1}{\beta} \exp \left(-\frac{1}{\beta}-\frac{U^{2} r_{d, i, j}^{2} \beta}{16 a_{s}^{2}}\right) d \beta$

The note $\varphi$ in Equation (15) is polar angle, which is indicated in Figure 9. As in the case of Equation (4), if the heat injection 
from the GHEX surface is considered to occur in a step-wise manner, Equation (15) can be rewritten as a simpler equation in the following manner.

$\Delta T_{s, i, j}\left(r_{d, i, j}, t\right) \cong \sum_{l=1}^{n} q_{l}\left\{\Delta T_{s-M I L S}\left(r_{d, i, j}, t-t_{l-1}\right)-\Delta T_{s-M I L S}\left(r_{d, i, j}, t-t_{l}\right)\right\}$

Also, if the dimensionless quantities $t_{d}^{*}=a_{s} t / r_{d}^{2}, R_{d}^{*}=U r_{d} / a_{s}$, and $T_{s-M L S}^{*}\left(R_{d}^{*}, t^{*}\right)=2 \pi \lambda_{s} \Delta T_{s-M I L S}\left(r_{d}, t\right) / q_{l}$ are adopted, Equation (16) is translated to the following equation.

$\Delta T_{s, i, j}\left(r_{d, i, j}, t\right) \cong \frac{1}{2 \pi \lambda_{s}} \sum_{l=1}^{n} q_{l}\left\{T_{s-M I L S}^{*}\left(R_{d, i, j}^{*}, t_{d, i, j}^{*}-t_{d, i, j, l-1}^{*}\right)-T_{s-M I L S}^{*}\left(R_{d, i, j}^{*}, t_{d, i, j}^{*}-t_{d, i, j, l}^{*}\right)\right\}$

Here,

$T_{S-M I L S}^{*}\left(R_{d, i, j}^{*}, t_{d, i, j}^{*}\right)=\frac{1}{2} \exp \left(\frac{R_{d, i, j}^{*}}{2} \cos \varphi\right) \int_{0}^{4 t_{d, i, j}^{*}} \frac{1}{\beta} \exp \left(-\frac{1}{\beta}-\frac{R_{d, i, j}^{* 2} \beta}{16}\right) d \beta$

\section{CALCULATI ON OF TEMPERATURE I NSI DE GHEX}

The heat carrier fluid in the GHEX is regarded as a lumped parameter system and the heat balance equation in the infinitesimal time $\mathrm{dt}$ is considered. The change in the heat capacity inside the GHEX can be thought as the sum of the heat input from the outside and the heat transferred from the ground. Hence the following expression holds.

$c_{p f} \rho_{f} V_{f} \frac{d T_{f}}{d t}=c_{p f} \rho_{f} G_{f}\left(T_{\text {pin }}-T_{\text {pout }}\right)+K_{p-\text { out }} A_{p-\text { out }}\left(T_{s}\left(r_{p-o u t}, t\right)-T_{f}\right)$

$K_{p-o u t}$ in Equation (19) is the overall heat transfer coefficient based on the outer surface area from the GHEX to the heat carrier fluid and $A_{p-o u t}$ is the outer surface area of the GHEX. Having determined $q_{l}$ for each instant from the formula $q=$ $K_{p-\text { out }} A_{p-\text { out }}\left(T_{s}\left(r_{p-o u t}, t\right)-T_{f}\right) / L_{p}$ and if the external surface temperature of the GHEX $T_{s}\left(r_{p-o u t}, t\right)=T_{s 0}+$ $\Delta T_{s}\left(r_{p-\text { out }}, t\right)$ is calculated using the method previously described in this paper, the temperature of inside GHEX and the underground temperature can be evaluated.

In order to calculate the overall heat transfer coefficient of the GHEX, the Boundary Elemental Method (BEM) was applied (Nagano et.al, 2006). If the the thermal resistance $R_{b}$ is calculated by BEM, the overall heat transfer coefficient $K_{p-o u t}$ is obtained by usng $R_{b}$ (Nagano et.al, 2006).

$K_{p-o u t}=\frac{A_{U-o u t}}{\left\{A_{U-\text { out }} R_{b}+A_{p-o u t} r_{U-o u t}\left(\frac{1}{\lambda_{U}} \ln \frac{r_{U-o u t}}{r_{U-i n}}+\frac{1}{r_{U-\text { in }} \alpha_{f}}\right)\right\}}$

$A_{U-\text { out }}$ is the external area of the U-tube, and $r_{U-\text { out }}$ and $r_{U-\text { in }}$ are the external and internal radius of the U-tube, respectively. Further, $\lambda_{U}$ is the thermal conductivity of the U-tube, and $\alpha_{f}$ is the convection heat transfer rate, which can be calculated by the method presented in the previous paper (Nagano et.al, 2006).

\section{CALCULATI ON OF TEMPERATURES CONSI DERI NG MULTI PLE GEOLOGI CAL LAYERS}

Figure 3 illustrates the multiple GHEXs buried in the ground with multiple geological layers. It is assumed that the heat transfer between the ground layers can be ignored. If the temperature changes on the surface of certain GHEX at every layer can be independently calculated, the temperature change at the layer $k$ is expressed by using the following equation.

$\Delta T_{s, i, k}\left(r_{p-o u t, i}, t\right)=\Delta T_{s, i, i, k}\left(r_{p-o u t, i}, t\right)+\sum_{j=1}^{m} \Delta T_{s, i, j, k}\left(r_{d, i, j}, t\right)$ 
The temperature changes $\Delta T_{s, i, i, k}\left(r_{p-o u t, i}, t\right)$ and $\Delta T_{s, i, j, k}\left(r_{d, i, j}, t\right)$ can be calculated as well as the calculation method previously explained.

The temperature of heat carrier fluid at each section in the GHEX are also independently calculated. The heat balance equation of heat carrier fluid in the supply pipe at the layer $k$ (the section number $k$ ) in Figure 11 is expressed by the following equation.

$$
\begin{gathered}
c_{p f} \rho_{f} V_{f, k} \frac{d T_{f, k}}{d t}=c_{p f} \rho_{f} G_{f}\left(T_{p i n, k}-T_{p o u t, k}\right)+ \\
\frac{K_{p-o u t} A_{p-o u t}}{2}\left(T_{s, k}\left(r_{p-o u t}, t\right)-T_{f, k}\right)
\end{gathered}
$$

Also, the heat balance equation of heat carrier fluid in the return pipe at the layer $k$ (the section number $2 n+1-k)$ in Figure 3 can be given as the following.

$c_{p f} \rho_{f} V_{f, 2 n+1-k} \frac{d T_{f, 2 n+1-k}}{d t}=$

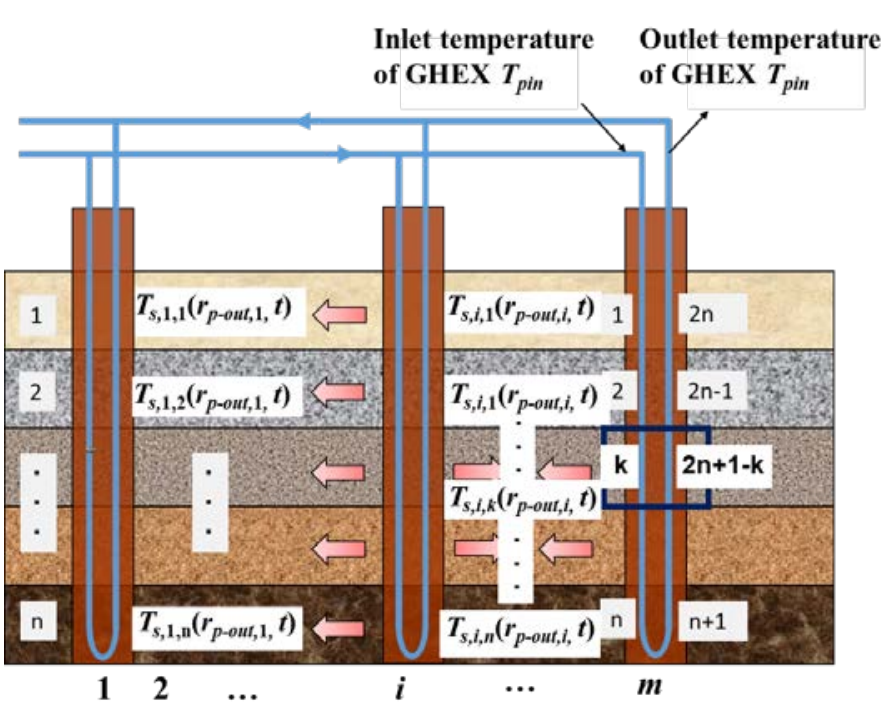

Figure 3 GHEXs buried in the ground with multiple geological layers

$c_{p f} \rho_{f} G_{f}\left(T_{p i n, 2 n+1-k}-T_{\text {pout }, 2 n+1-k}\right)+\frac{K_{p-o u t} A_{p-o u t}}{2}\left(T_{s, 2 n+1-k}\left(r_{p-o u t}, t\right)-T_{f, 2 n+1-k}\right)$

The heat injection rate at the layer $k q_{k}$ is calculated by using the following equation.

$q_{k}=-\pi r_{p-o u t}\left\{K_{p-\text { out }}\left(T_{s, k}\left(r_{p-\text { out }}, t\right)-T_{f, k}\right)+K_{p-\text { out }}\left(T_{s, k}\left(r_{p-\text { out }}, t\right)-T_{f, 2 n+1-k}\right)\right\}$

\section{EXAMPLE OF PERFORMANCE PREDICTI ON OF GROUND SOURCE HEAT PUMP SYSTEM}

\section{Calculation conditions}

Considering the case of a GSHP system affected by the groundwater flow installed in an office building in Akita prefecture, Japan, the temperature change in the GSHP system was predicted. The calculation conditions are shown in Figure 4. The GSHP unit with the heating and cooling output of around $30 \mathrm{~kW}$ is connected to 4 borehole GHEXs with $100 \mathrm{~m}$ depth. The underground temperature and the effective thermal conductivity without groundwater flow were given as $12.0{ }^{\circ} \mathrm{C}$ and $2.0 \mathrm{~W} /(\mathrm{m} \cdot \mathrm{K})$, respectively. The three types of geological conditions shown in Figure 5 were provided. CASE $\mathrm{A}$ is the single geological layer without groundwater flow. CASE B is the double geological layers and the upper layer have the groundwater flow with the velocity of $1000 \mathrm{~m} /$ year. CASE $\mathrm{C}$ is the single layer with the groundwater flow and the velocity is $1000 \mathrm{~m} /$ year. The hourly thermal load shown in Figure 6 was assigned every hour and the external surface temperature of the GHEX $T_{s}\left(r_{p-\text { out }}, t\right)=T_{s 0}+$ $\Delta T_{s}\left(r_{p-o u t}, t\right)$ and the inlet temperature in the primary side of GSHP unit $T_{1 \text { in }}$ were calculated (Nagano et.al, 2006).

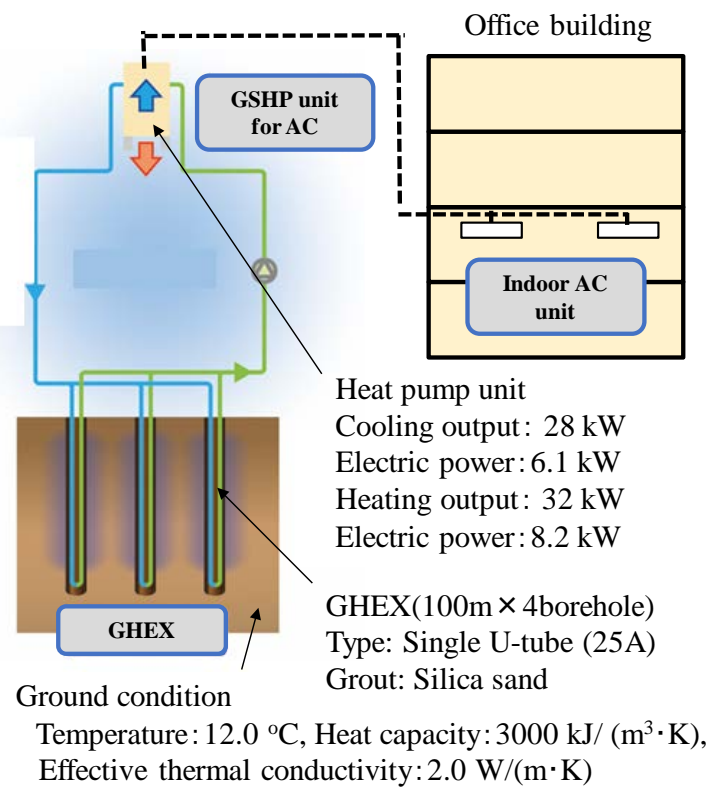

Figure 4 GSHP system installed in office building 


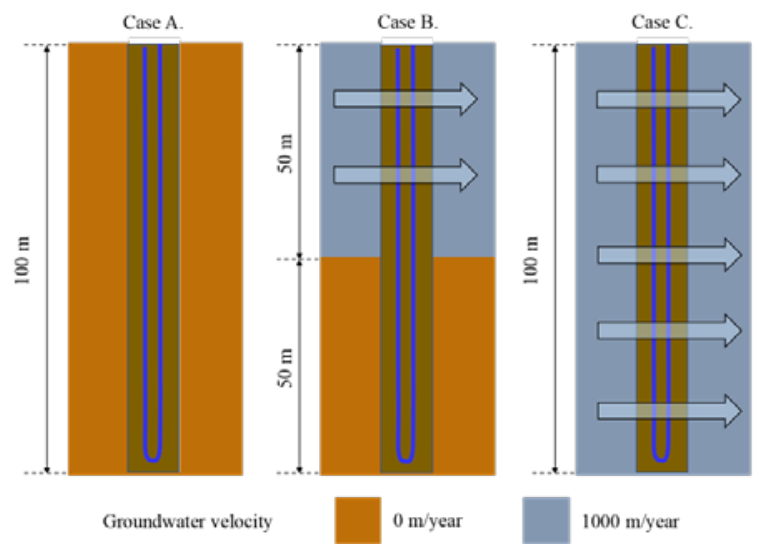

Figure 5 Conditions of geological layer

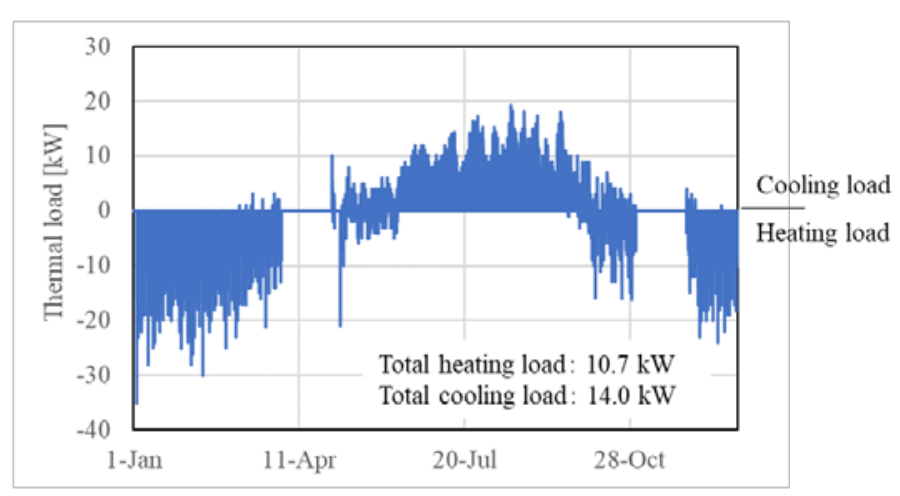

Figure 6 Hourly thermal load in annual

\section{Result and discussions}

Figure 7 compares the hourly variations of $T_{s}\left(r_{p-o u t}, t\right)$. In CASE $\mathrm{A}$, the temperature $T_{s}\left(r_{p-o u t}, t\right)$ is around $8{ }^{\circ} \mathrm{C}$ at the minimum and around $20^{\circ} \mathrm{C}$ at the maximum. On the other hand, the temperature $T_{s}\left(r_{p-o u t}, t\right)$ in CASE $\mathrm{C}$ ranges from $10^{\circ} \mathrm{C}$ to 14 ${ }^{\circ} \mathrm{C}$. The reason is that the temperature change occurred by heat injection/extraction into/from GHEX is smaller when the groundwater flow is generated. The temperature $T_{s}\left(r_{p-o u t}, t\right)$ at upper layer in CASE B is almost the same as the temperature $T_{s}\left(r_{p-o u t}, t\right)$ in CASE $\mathrm{C}$ and the temperature change of $T_{S}\left(r_{p-o u t}, t\right)$ at bottom layer in CASE B is alike the temperature change of $T_{s}\left(r_{p-o u t}, t\right)$ in CASE A. Also, the hourly variations of

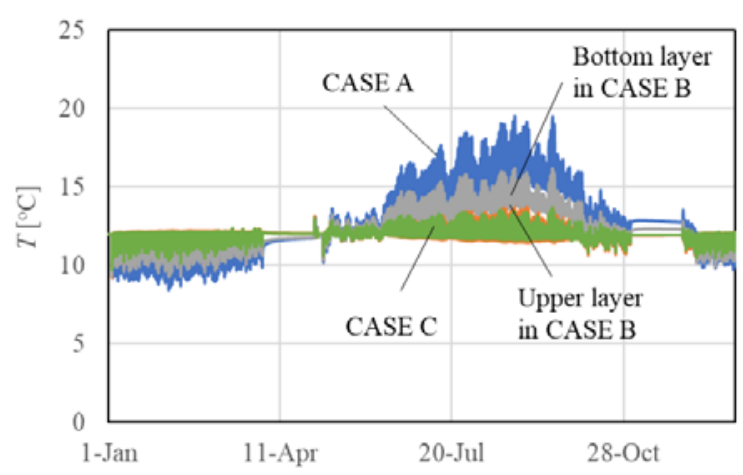

Figure 7 Hourly variation of $T_{s}\left(r_{p-o u t}, t\right)$ in annual $T_{s}\left(r_{p-\text { out }}, t\right)$ in the representative period (Aug. $18 \sim$ Aug. 19) are shown in Figure 8. The temperature $T_{s}\left(r_{p-\text { out }}, t\right)$ at upper layer in CASE B and $T_{s}\left(r_{p-o u t}, t\right)$ in CASE C decrease to $12{ }^{\circ} \mathrm{C}$, which is the initial ground temperature, if the GSHP system is not operated. This is due to the effect of groundwater advection. Finally, Figure 9 shows the hourly variation of $T_{1 i n}$.

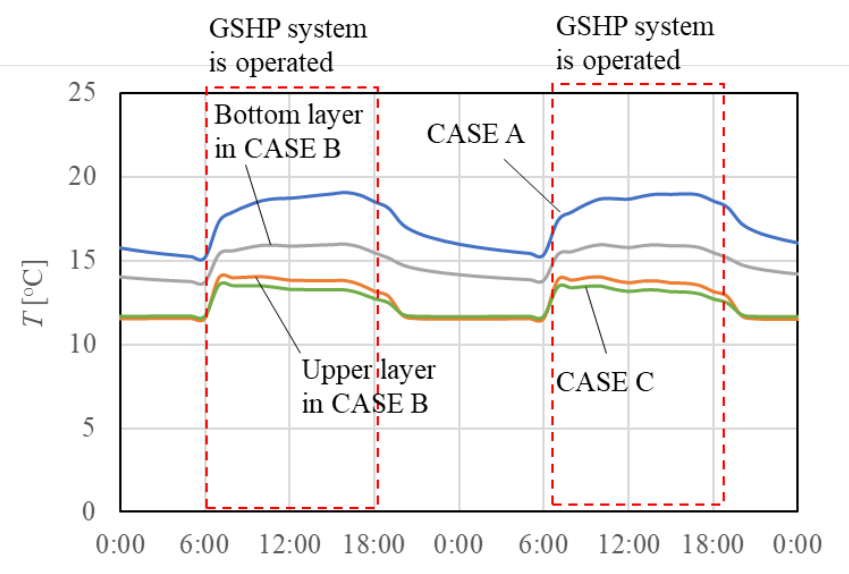

Figure 8 Hourly variation of $T_{S}\left(r_{p-o u t}, t\right)$ in the representative period (Aug. $18 \sim$ Aug. 19)

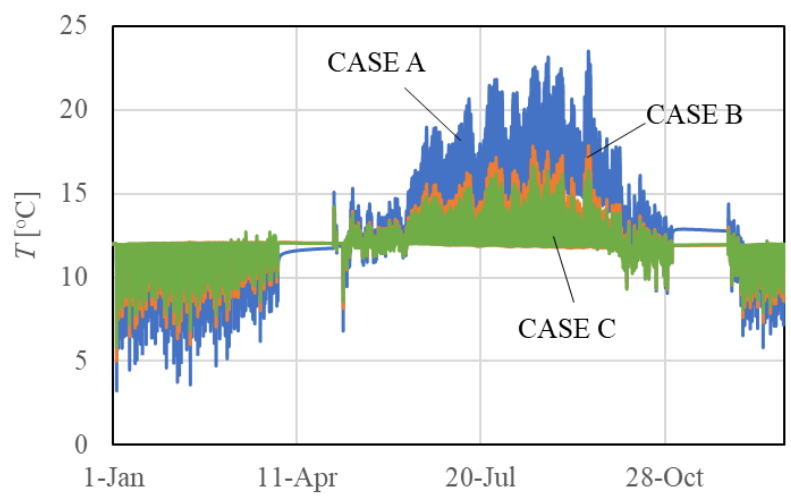

Figure 9 Hourly variation of $T_{1 \text { in }}$ in annual 
The temperature variation of $T_{1 \text { in }}$ is also smaller when the groundwater flow is generated. Then, the temperature variation is smaller when the thickness of layer in which the groundwater flow is generated becomes larger. From this result, it seems that the GSHP system can be operated even if the number of GHEXs is reduced in CASE B and CASE C. Therefore, it is indicated that the total length of GHEX can be reduced by considering the groundwater flow in the design of GSHP system.

\section{CONCLUSION}

1) It is shown that the heat transfer in the porous media with Darcy flow surrounding cylinder can be expressed by applying the MICS and the MILS if the radius of cylinder is small. In addition, in order to calculate the MICS solution in short time, the method in which the modification coefficient is multiplied to the ICS analytical solution.

2) The calculation method of the underground temperature that can consider the heat injection/extraction into/from the GHEXs was introduced. The method applies the superposition of the MICS solution and the MILS solution.

3) Considering the case of a GSHP system installed in an office building, the conditions of geological layer and groundwater velocity were changed and the temperature changes of the ground and the heat carrier fluid in the primary side were calculated. The result shows that the temperature changes of the ground with groundwater flow is smaller than the temperature changes of the ground without groundwater flow. Therefore, it is indicated that the total length of GHEX can be reduced by considering the groundwater flow in the design of GSHP system.

\section{ACKNOWLEDGMENTS}

This study is based on results obtained from the project "Renewable energy heat utilization technology development," commissioned by the Japan national agency New Energy and Industrial Technology Development Organization (NEDO).

\section{NOMENCLATURE}
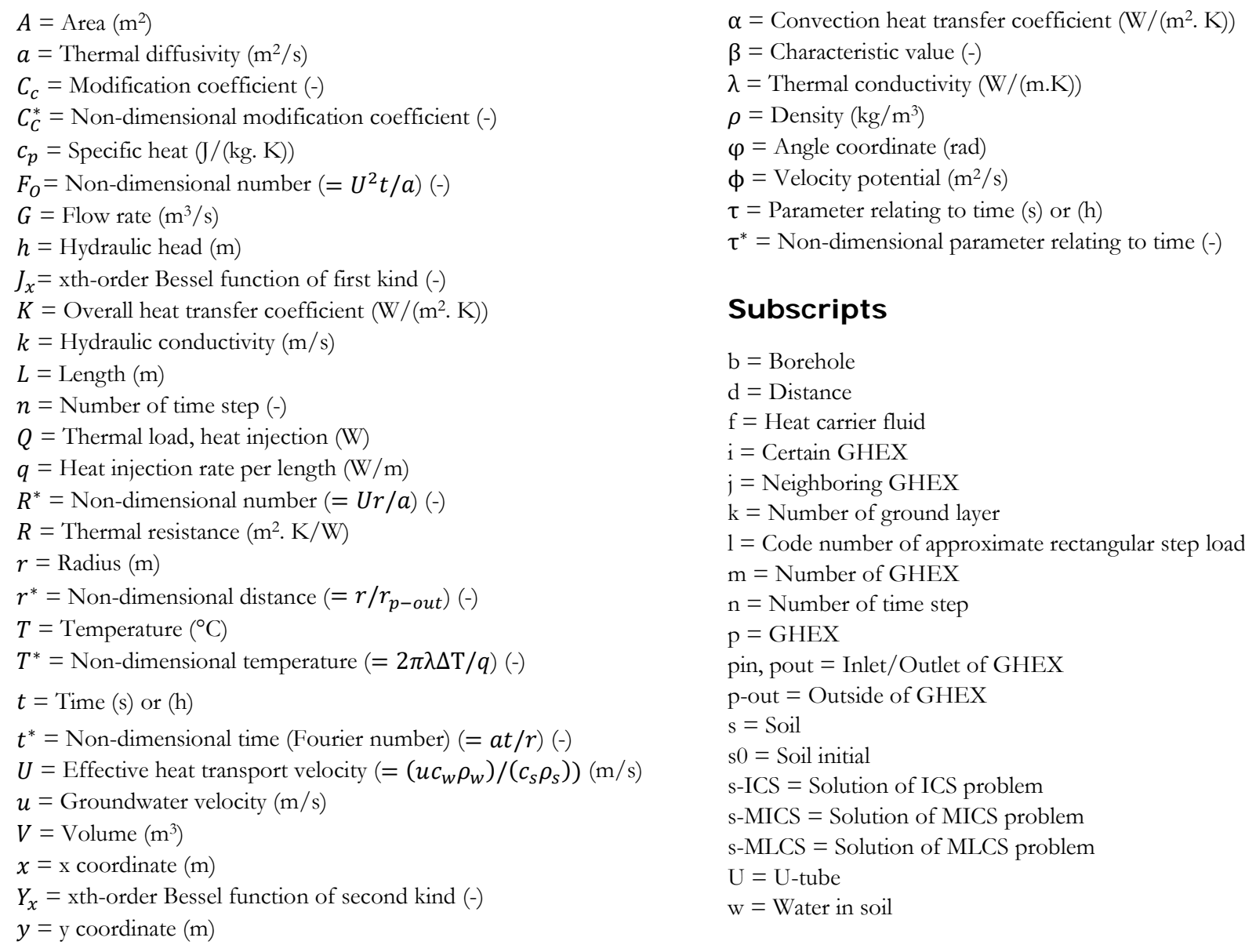

\section{Subscripts}

$\mathrm{b}=$ Borehole

$\mathrm{d}=$ Distance

$\mathrm{f}=$ Heat carrier fluid

$\mathrm{i}=$ Certain GHEX

$\mathrm{j}=$ Neighboring GHEX

$\mathrm{k}=$ Number of ground layer

$1=$ Code number of approximate rectangular step load

$\mathrm{m}=$ Number of GHEX

$\mathrm{n}=$ Number of time step

$\mathrm{p}=\mathrm{GHEX}$

pin, pout $=$ Inlet $/$ Outlet of GHEX

p-out $=$ Outside of GHEX

$\mathrm{s}=$ Soil

$\mathrm{s} 0=$ Soil initial

s-ICS $=$ Solution of ICS problem

s-MICS $=$ Solution of MICS problem

s-MLCS $=$ Solution of MLCS problem

$\mathrm{U}=\mathrm{U}$-tube

$\mathrm{w}=$ Water in soil 


\section{REFERENCES}

Abramowitz, M. and Stegun, I.: Hand book of Mathematical Functions 7th Edition, Dover Publications, New York, p.1046, 1970.

Bruce R. Munson, D. F. Young, T. H. Okiishi, W. W. Huebsch : Fundamentals of Fluied Mechanics, sixth ed., Johon Wiley \& Sons, Inc, Hoboken, 2009

Carslaw H.S. and J. C. Jaeger: Conduction of Heat in Solid, Oxford Unversity Press, 1959.

Conti. P, D. Testi, W. Grassi : Transient forced convection from an infinite cylindrical heat source in a saturated Darcian porous medium, International Journal of Heat and Mass Transfer 117, pp.154-166, 2018.

Diao. N, Q. Li, Z. Fang : Heat Transfer in Ground Heat Exchangers with Groundwater Advection, International Journal of Thermal Sciences 43, pp.1203-1211, 2004.

Gehlin. S., G. Hellström : Influence on Thermal Response Test by Groundwater Flow in Vertical Fractures in Hard Rock, Renewable Energy 28, pp.2221-2238, 2003.

Hantush, M. S.: Analysis of data from pumping tests in leaky aquifers, Transactions American Geophysical Union 37, pp.702$714,1956$.

Henry, T. F. and Foree, E. G.: Dispersion modeling in time and two dimensions, Journal of the Environmental Engineering Division 10, pp.1131-1147, 1979.

Katsura T., K. Nagano, S. Takeda, K. Shimakura: Heat transfer experiment in the ground with ground water advection, Proceeding of $10^{\text {th }}$ international conference of energy strorage Ecostock, Galloway, New Jersey, 2006.

Katsura T., K. Nagano, S. Takeda, Y. Nakamura: An investigation on relation between ground water advection and thermal response by the thermal probe method, Transactions of the Society of Heating, Air-conditioning and Sanitary Engineering of Japan, No.112, pp.51-60, 2006 (In Japanese).

Katsura T., K. Nagano, S. Takeda, Y. Nakamura: Method of calculation of the ground temperature with ground water flow and its application, Transactions of the Society of Heating, Air-conditioning and Sanitary Engineering of Japan, No.115, pp.9-18, 2006 (In Japanese).

Katsura T., K. Nagano, Y. Sakata, T. Higashitani: A Design and Simulation Tool for Ground Source Heat Pump System and Borehole Thermal Storage System, Proceeding of $14^{\text {th }}$ international conference of energy strorage Enerstock, Adana, Turkey, 2018.

Li S., Kefeng Dong, Jinyong Wang, Xiaosong Zhang: Long term coupled simulation for ground source heat pump and underground heat exchangers, Energy and buildings 106, pp.13-22, 2015.

Molina-Giraldo.N, P. Blum, K. Zhu, P. Bayer, Z. Fang : A moving finite line source model to simulate borehole heat exchangers with groundwater advection, International Journal of Thermal Sciences 50, pp.2506-2513, 2011.

Nagano K., T. Katsura and S. Takeda: Development of a Design and Performance Prediction Tool for the Ground Source Heat Pump System, Applied Thermal Engineering, Volume 26, Issues 14-15, pp.1578-1592, 2006. 